\title{
ПРЕВРАЩЕНИЯ АЗОТОРГАНИЧЕСКИХ ОСНОВАНИЙ СМОЛИСТЫХ КОМПОНЕНТОВ НЕФТИ КРАПИВИНСКОГО МЕСТОРОЖДЕНИЯ ПРИ ТЕРМИЧЕСКОМ ВОЗДЕЙСТВИИ
}

\author{
Герасимова Наталья Николаевна', \\ dm@ipc.tsc.ru
}

\author{
Сагаченко Татьяна Анатольевна', \\ dissovet@ipc.tsc.ru
}

\author{
Мин Раиса Сергеевна', \\ lgosn@ipc.tsc.ru \\ ' Институт химии нефти Сибирского отделения Российской академии наук, \\ 634055, г. Томск, пр. Академический, 4.
}

Актуальность работы обусловлена необходимостью получения информации о термической устойчивости азоторганических оснований смолистых компонентов верхнеюрской метано-нафтеновой нефти месторождения Крапивинское, расположенного на территории Томской области, для решения проблем, связанных с ее переработкой.

Цель работы: получение данных о направлениях термических превращений азоторганических оснований смол нефти Крапивинского месторождения.

Методы исследования: комплексообразование, экстракция, ЯМР 'H спектроскопия, структурно-групповой анализ, хроматомасс-спектрометрия.

Результаты. На основании изучения состава и структуры азоторганических оснований смол нефти Крапивинского месторождения до и после термического воздействия $\left(450^{\circ} \mathrm{C}, 30\right.$ мин, инертная среда) показано, что при термолизе в выбранных условиях происходит частичная деструкция высокомолекулярных оснований и полная потеря низкомолекулярных оснований. Все основания в термолизованных смолах являются продуктами превращения высокомолекулярных соединений исходных смол. Установлено, что большую часть оснований в смолах до и после термической обработки составляют высокомолекулярные соединения, однако их доля в термолизованных смолах существенно ниже. Термопреобразованные основания имеют меньшие средние молекулярные массы, чем исходные. Состав выделенных соединений исследован методами структурно-группового анализа и газовой хроматомасс-спектрометрии. Показано, что средние молекулы азоторганических оснований обоих типов смол построены из ароматических, нафтеновых и алкильных фрагментов. В средних молекулах соединений термолизованных смол более высока доля ароматических атомов углерода за счет снижения доли нафтеновых и алкильных углеродных атомов. В составе оснований исходных и термолизованных смол присутствуют алкилпроизводные хинолина, бензохинолина, дибензохинолина и азапирена, среди которых преобладают алкилбензохинолины. Особенностью азааренов термолизованных смол является повышенное содержание алкилхинолинов. Для термопреобразованных структур характерно менее развитое алкильное замещение и более высокая доля в их составе низкомолекулярных гомологов.

\section{Ключевые слова:}

Смолы, азоторганические основания, термические превращения, содержание, состав, структурно-групповой анализ, хроматомасс-спектрометрия.

\section{Введение}

Представленная работа является продолжением исследований по характеристике смолистых компонентов метано-нафтеновой нефти Крапивинского месторождения $[1,2]$, которое по прогнозным запасам $(36,5$ млн т) является одним их крупнейших на территории Томской области и на данный момент находится в промышленной разработке. Содержание смол в крапивинской нефти составляет 8,8 \% [1]. Поэтому они по праву считаются перспективным резервом углубления ее переработки. В связи с этим большое значение имеют данные о поведении смолистых компонентов в процессе термического воздействия на нефтяную систему. Особый интерес представляют результаты термического преобразования азоторганических оснований (A0) смол, так как присутствие этих соединений в углеводородном сырье оказывает негативное влияние на процессы каталитического облагораживания дистиллятных фракций, качество и эксплуатационные характеристики горюче-смазоч- ных материалов, окружающую среду и здоровье человека [3-8]. В связи с этим публикации последних лет посвящены главным образом разработке методов удаления азотистых соединений из нефтяного сырья [3]. Информация о структурных изменениях АО под воздействием температуры касается их устойчивости в процессах гидроочистки дистиллятных фракций $[9,10]$ и моделирования процессов термического созревания для решения проблем геохимии $[11,12]$. Сведения о трансформации АО смол в термических процессах на сегодняшний день в литературе отсутствуют.

Цель настоящего исследования - получение данных о направлениях термических превращений АО смол нефти Крапивинского месторождения.

\section{Экспериментальная часть}

Объекты исследования - АО исходных смол крапивинской нефти и АО смол после их термической обработки при $450{ }^{\circ} \mathrm{C}$ в течение 30 мин в инертной среде. Температура и время термолиза 
смол установлены на основании результатов дифференциального термического анализа (ДТА) концентрата высокомолекулярных оснований, составляющих основную массу нефтяных АО $[2,13,14]$. Термические превращения низкомолекулярных оснований по данным ДТА завершаются при температуре $350{ }^{\circ} \mathrm{C}$. Следовательно, АО в термолизованных смолах являются продуктами деструкции высокомолекулярных оснований исходных смол.

АО выделяли из гексановых растворов исходных и термолизованных смол по схеме [2], применение которой позволяет получить концентраты высокомолекулярных соединений (К-1), (К-2), различающихся по молекулярной массе, и концентрат низкомолекулярных оснований $(\kappa-3)$ и разделить основания $\mathrm{K}-1$ и $\mathrm{K}-2$ методом горячей экстракции н-гексаном на растворимые $\left(\kappa-1^{\text {ГР }}\right.$ и $\left.\kappa-2^{\text {ГР }}\right)$ и нерастворимые $\left(\kappa-1^{\text {гнР }}\right.$ и $\left.K-2^{\text {гнР }}\right)$ в нем компоненты.

Элементный анализ образцов проводили на автоматическом анализаторе $\mathrm{C}, \mathrm{H}, \mathrm{S}, \mathrm{N}$ «Vario EL Cube». Абсолютная погрешность анализатора не превышала $\pm 0,1 \%$ для каждого определяемого элемента. Содержание кислорода оценивали по разности между 100 \% и суммой элементов: C, H, $\mathrm{N}, \mathrm{S}$.

Функциональный анализ азотистых соединений проводили методом неводного потенциометрического титрования [15].

Средние молекулярные массы (MМ) измеряли методом криоскопии в бензоле [16].

Спектры ЯМР ${ }^{1} \mathrm{H}$ записывали на спектрометре ЯMР-Фурье «AVANCE AV 300» фирмы «Bruker» при 300 МГц в растворах $\mathrm{CDCl}_{3}$. В качестве стандарта использовали тетраметилсилан. По спектрам ЯМР ${ }^{1} \mathrm{H}$ проводили расчет относительного содержания протонов в различных структурных фрагментах, исходя из площадей сигналов в соответствующих областях спектра: $H_{\mathrm{ar}}$ (доля протонов, содержащихся в ароматических структурах) $6,6 . . .8,5 \mathrm{ppm} ; H_{\alpha}$ (доля протонов у атома углерода в $\alpha$-положении алифатических заместителей ароматических структур) $-2,2 . .4,0 \mathrm{ppm} ; H_{\beta}$ и $H_{\gamma}$ (доля протонов в метиленовых и в концевых метильных группах алифатических фрагментов молекул, соответственно) - 1,1...2,1 и 0,3...1,1 ppm [17].

На основе данных о МM, элементном составе и распределении протонов между различными фрагментами молекул рассчитывали средние структурные характеристики молекул смол [18]. В ходе расчетов определены следующие параметры: $\mathrm{C}_{a}$ $\mathrm{C}_{\mathrm{n}}, \mathrm{C}_{\mathrm{p}}$ - число атомов углерода в ароматических, нафтеновых и парафиновых структурах средней молекулы; $f_{\mathrm{a}}, f_{\mathrm{n}}, f_{\mathrm{p}}$ - доли атомов углерода в ароматических, нафтеновых и парафиновых структурных фрагментах; $\mathrm{m}_{\mathrm{a}}$ - число структурных единиц в средней молекуле; $K_{t}{ }^{*}, \kappa_{\mathrm{a}}{ }^{*}, \mathrm{~K}_{\mathrm{n}}{ }^{*}$ - общее число, число ароматических и нафтеновых циклов в структурной единице; $\mathrm{C}_{\mathrm{p}}$ * - число атомов углерода в парафиновых фрагментах структурной единицы; $\mathrm{C}_{\alpha}$ * и $\mathrm{C}_{\gamma}$ * - количество атомов углерода, находящихся в $\alpha$-положении к ароматическим ядрам и в не связанных с ароматическими ядрами терминальных метильных группах.

Концентраты К- $1^{\text {гР }}, \kappa-2^{\text {гР }}$ и $\mathrm{K}-3$ анализировали методом хроматомасс-спектрометрии (ГХ-МС) на приборе DFS фирмы «Thermo Scientific» при энергии ионизирующих электронов $70 \mathrm{eV}$, температуре ионизационной камеры $270{ }^{\circ} \mathrm{C}$, температуре интерфейса $270{ }^{\circ} \mathrm{C}$, температуре инжектора $250{ }^{\circ} \mathrm{C}$. Для хроматографического разделения использовалась колонка длиной $30 \mathrm{~m}$, диаметром $0,25 \mathrm{~mm}$, с толщиной фазы DB-5MS 0,25 мкм. Газ-носительгелий при постоянном расходе 0,8 мл/мин. Программа термостата: начальная температура $-80{ }^{\circ} \mathrm{C}$ (3 мин), подъем до $300{ }^{\circ} \mathrm{C}\left(4^{\circ} \mathrm{C} /\right.$ мин $)$, выдержка при конечной температуре - 30 мин. Сканирование масс-спектров осуществлялось каждую секунду в диапазоне масс до 500 а.е.м. Реконструкцию молекулярно-массового разделения (масс-хроматограмм) различных типов УВ проводили с использованием характеристических ионов на основе хроматограмм по полному ионному току с помощью программы Xcalibur. Для идентификации индивидуальных соединений использовали компьютерную библиотеку масс-спектров NIST 02.

Анализ образцов осуществляли с привлечением оборудования центра коллективного пользования Томского научного центра СО РАН.

\section{Результаты и их обсуждение}

Продуктами термической обработки смол в выбранных условиях являются газообразные $(1,2 \%)$, твердые, коксоподобные $(5,0 \%)$ и растворимые в бензоле $(93,8$ \%) соединения. Последние представлены «вторичными» асфальтенами $(7,0 \%$ отн.) и мальтенами $(86,8$ \% отн., далее термолизованные смолы).

Сравнительный анализ полученных данных показывает, что термолизованные смолы отличаются от исходных более низкими концентрациями общего $\left(\mathrm{N}_{\text {общ }}\right)$ и основного $\left(\mathrm{N}_{\text {осн }}\right)$ азота (табл. 1$)$. Снижение в термолизованных смолах содержания $\mathrm{N}_{\text {общ }}$ (в 1,2 раза) и $\mathrm{N}_{\text {осн }}$ (в 1,8 раза) подтверждает данные авторов [11, 19-21], что азотистые соединения, в частности A0, участвуют в формировании коксоподобных продуктов, образующихся в процессе термолиза нефтяного сырья.

Особеностью термолизованных смол является также более низкое суммарное количество выделенных из них концентратов АО (10,03 против $26,08 \%$ мас.) и доля связанного с ними $\mathrm{N}_{\text {осн }}$ (69,1 против 84,3 \% отн.) (табл. 2). Различие в относительном содержании основного азота может быть связано с образованием в процессе термолиза смол оснований, структурные особенности которых препятствуют их выделению применяемыми методами. Большую часть оснований, выделенных из обоих типов смол, составляют высокомолекулярные соединения $\mathrm{K}-1$ и К-2. Однако в термолизованных смолах их массовая доля $(9,01 \%$ мас.) и доля связанного с ними $\mathrm{N}_{\text {осн }}(53,3 \%$ отн.) ниже, 
чем в исходных смолах $(24,14 \%$ мас. и $69,9 \%$ отн. соответственно). Следует отметить, что термическим преобразованиям в большей степени подвергаются высокомолекулярные соединения К-2. В процессе термолиза смол их количество снижается наиболее существенно (с 13,21 до $0,30 \%$ мас.). Концентраты низкомолекулярных оснований $\mathrm{K}$ 3 исходных и термолизованных смол по выходу и относительному содержанию $\mathrm{N}_{\text {осн }}$ в структуре их оснований различаются незначительно.

Продукты, полученные из термолизованных смол, характеризуются меньшими значениями MM, по сравнению с одноименными продуктами исходных смол (табл. 2).

Таблица 1. Распределение общего и основного азота в исходных и термолизованных смолах крапивинской нефти

Table 1. Distribution of total and basic nitrogen in the initial and thermolysed resins recovered from the Krapivinsk oil

\begin{tabular}{|c|c|c|c|c|c|}
\hline \multirow[b]{3}{*}{$\begin{array}{l}\text { Образцы } \\
\text { Samples }\end{array}$} & \multirow{3}{*}{ 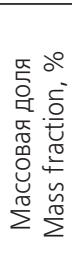 } & \multicolumn{4}{|c|}{ Содержание/Content } \\
\hline & & \multicolumn{2}{|c|}{$\mathrm{N}_{\text {общ }} / \mathrm{N}_{\text {tot }}$} & \multicolumn{2}{|c|}{$\mathrm{N}_{\text {och }} / \mathrm{N}_{\text {bas }}$} \\
\hline & & 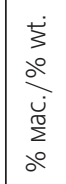 & 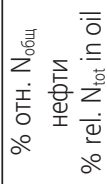 & 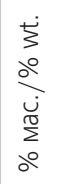 & 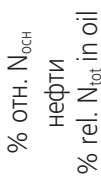 \\
\hline $\begin{array}{l}\text { Исходные смолы } \\
\text { Initial resins }\end{array}$ & 8,78 & 0,56 & 23,5 & 0,25 & 64,7 \\
\hline $\begin{array}{l}\text { Tермолизованные смолы } \\
\text { Thermolysed resins }\end{array}$ & 7,62 & 0,46 & 16,7 & 0,14 & 31,4 \\
\hline
\end{tabular}

Таблица 2. Характеристика азоторганических оснований исходных и термолизованных смол

Table 2. Characterization of organic nitrogen bases in the initial and thermolysed resins

\begin{tabular}{|c|c|c|c|c|c|c|}
\hline \multirow{4}{*}{$\begin{array}{l}\text { Показатели } \\
\text { Indicators }\end{array}$} & \multicolumn{6}{|c|}{ Образцы/Samples } \\
\hline & \multicolumn{3}{|c|}{$\begin{array}{l}\text { Смолы исходные } \\
\text { Initial resins }\end{array}$} & \multicolumn{3}{|c|}{$\begin{array}{c}\text { Смолы } \\
\text { термолизованные } \\
\text { Themolysed resins }\end{array}$} \\
\hline & $\mathrm{K}-1$ & $\mathrm{~K}-2$ & $\mathrm{~K}-3$ & $\mathrm{~K}-1$ & $\mathrm{~K}-2$ & $\mathrm{~K}-3$ \\
\hline & K-1 & $K-2$ & $K-3$ & K-1 & $K-2$ & $K-3$ \\
\hline $\begin{array}{l}\text { Массовая доля } \\
\text { Mass fraction, \% }\end{array}$ & 10,93 & 13,21 & 1,94 & 8,71 & 0,30 & 1,02 \\
\hline MM, a.e.м./a.m.u. & 1018 & 607 & 383 & 683 & 413 & 330 \\
\hline $\begin{array}{l}\text { Массовая доля } \mathrm{N}_{\text {общ }} \\
\text { Mass fraction } \mathrm{N}_{\text {tot, }} \%\end{array}$ & 1,29 & 1,73 & 2,20 & 1,67 & 2,12 & 3,02 \\
\hline $\begin{array}{l}\text { Доля } \mathrm{N}_{\text {общ Смол }} \\
\text { Fraction of } \mathrm{N}_{\text {tot }} \text { resins, \% }\end{array}$ & 25,2 & 40,9 & 7,6 & 31,6 & 1,4 & 6,7 \\
\hline $\begin{array}{l}\text { Массовая доля } \mathrm{N}_{\text {осн }} \\
\text { Mass fraction } \mathrm{N}_{\text {bas }}, \%\end{array}$ & 0,73 & 0,72 & 1,86 & 0,83 & 0,79 & 2,21 \\
\hline $\begin{array}{l}\text { Доля } \mathrm{N}_{\text {осн }} \text { смол } \\
\text { Fraction of } \mathrm{N}_{\text {bas }} \text { resins, \% }\end{array}$ & 31,8 & 38,1 & 14,4 & 51,6 & 1,7 & 15,9 \\
\hline
\end{tabular}

Согласно результатам фракционирования, АО концентратов К-1 и К-2 исходных и термолизованных смол различаются по содержанию соединений, растворимых и нерастворимых в гексане (табл. 3). Процесс термодеструкции сопровождается увеличением доли гексанорастворимых продуктов. Так, в случае исходных смол относительное содержание $\mathrm{K}-1^{\mathrm{TP}}$ и $\mathrm{K}-2^{\mathrm{rP}}$ составляет 34,4 и $30,8 \%$ отн. соответственно, а в случае термолизованных смол - 43,6 и 40,0 \% отн. Для обоих типов смол значения MМ соединений $\mathrm{K}-1^{\mathrm{rP}}$ и $\mathrm{K}-2^{\mathrm{IP}}$ существенно ниже значений $\mathrm{MM}$ соединений $K-1^{\mathrm{rHP}}$ и $\mathrm{K}-2^{\text {rнР }}$. В то же время продукты, полученные из термолизованных смол, имеют более низкие значения МM, чем одноименные продукты, выделенные из исходных смол. Выявленные различия могут быть связаны с протеканием при термодеструкции реакций деалкилирования и отрыва и/или раскрытия нафтеновых циклов, приводящих к образованию более низкомолекулярных соединений $[11,20,21]$. Участвовать в этих реакциях могут АО, входящие в состав К-1 и К-2 исходных смол.

Таблица 3. Экстракционное разделение высокомолекулярных азоторганических оснований исходных и термолизованных смол

Table 3. Extractive separation of high-molecular organic nitrogen bases in the initial and thermolysed resins

\begin{tabular}{|c|c|c|c|c|c|c|c|c|}
\hline \multirow{3}{*}{$\begin{array}{l}\text { Показатели } \\
\text { Indicators }\end{array}$} & \multicolumn{8}{|c|}{ Образцы/Samples } \\
\hline & \multicolumn{4}{|c|}{$\begin{array}{l}\text { Смолы исходные } \\
\text { Initial resins }\end{array}$} & \multicolumn{4}{|c|}{\begin{tabular}{|c|} 
Смолы \\
термолизованные \\
Thermolysed resins
\end{tabular}} \\
\hline & 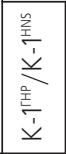 & 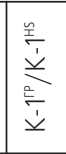 & 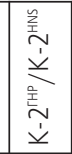 & 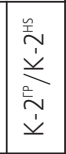 & 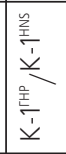 & 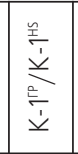 & 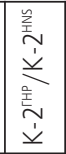 & 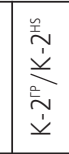 \\
\hline \begin{tabular}{|l} 
Массовая доля \\
Mass fraction, \%
\end{tabular} & 7,17 & 3,76 & 9,14 & 4,07 & 4,91 & 3,80 & 0,18 & 0,12 \\
\hline MM, a.e.м./a.m.u. & 1200 & 670 & 709 & 379 & 794 & 540 & 469 & 329 \\
\hline $\begin{array}{l}\text { Массовая доля } \mathrm{N}_{\text {общ }} \\
\text { Mass fraction } \mathrm{N}_{\text {tot, }} \%\end{array}$ & 1,14 & 1,58 & 1,91 & 1,34 & 1,46 & 1,96 & 2,01 & 2,19 \\
\hline $\begin{array}{l}\text { Доля } \mathrm{N}_{\text {общ }} \text { смол } \\
\text { Fraction of } \mathrm{N}_{\text {tot }} \text { resins, } \\
\%\end{array}$ & 14,6 & 10,6 & 31,2 & 9,7 & 15,5 & 16,1 & 0,8 & 0,6 \\
\hline $\begin{array}{l}\text { Массовая доля } \mathrm{N}_{\text {осн }} \\
\text { Mass fraction } \mathrm{N}_{\text {bas, }} \%\end{array}$ & 0,57 & 1,03 & 0,54 & 1,13 & 0,71 & 0,98 & 0,75 & 0,82 \\
\hline $\begin{array}{l}\text { Доля } \mathrm{N}_{\text {осн }} \text { Смол } \\
\text { Fraction of } \mathrm{N}_{\text {bas }} \text { resins, } \\
\%\end{array}$ & 16,3 & 19,7 & 15,5 & 18,4 & 24,9 & 26,6 & 1,1 & 0,6 \\
\hline
\end{tabular}

Сопоставление данных структурно-группового анализа позволило установить сходства и различия в структуре АО исходных и термолизованных смол. Приведенные в табл. 4 расчетные параметры свидетельствуют, что средние молекулы соедине-

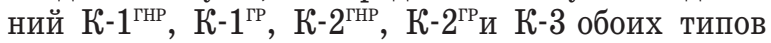
смол образуют системы, состоящие из ароматических $\left(\mathrm{C}_{\mathrm{a}}\right)$, нафтеновых $\left(\mathrm{C}_{\mathrm{n}}\right)$ и парафиновых $\left(\mathrm{C}_{\mathrm{p}}\right)$ структурных фрагментов.

Во всех образцах большая часть общего числа углеродных атомов $(57,4 \ldots 73,4 \%)$ приходится на насыщенные фрагменты $\left(f_{n}+f_{\mathrm{p}}\right)$, доля углерода ароматического характера $\left(f_{\text {a }}\right)$ составляет $26,6 \ldots . .42,6 \%$. При этом средние молекулы АО термолизованных 
смол, как правило, более ароматичны за счет снижения доли нафтеновых $\left(f_{n}\right)$ и/или парафиновых $\left(f_{p}\right)$ углеродных атомов.

Таблица 4. Расчетные значения важнейших структурных параметров молекул азоторганических оснований исходных и термолизованных смол

Table 4. Calculated values of the most important structural parameters for the molecules of organic nitrogen bases in the initial and thermolysed resins

\begin{tabular}{|c|c|c|c|c|c|c|c|c|c|c|}
\hline \multirow{4}{*}{ 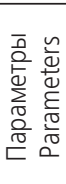 } & \multicolumn{10}{|c|}{ Образцы/Samples } \\
\hline & \multicolumn{5}{|c|}{$\begin{array}{l}\text { Смолы исходные } \\
\text { Initial resins }\end{array}$} & \multicolumn{5}{|c|}{$\begin{array}{l}\text { Смолы термолизованные } \\
\text { Thermolysed resins }\end{array}$} \\
\hline & $\mathrm{K}-1^{\text {ГमP }}$ & $\mathrm{K}-1^{\mathrm{TP}}$ & $\mathrm{K}-2^{\text {ГHP }}$ & $K-2^{\Gamma P}$ & K-3 & $\mathrm{K}-1^{\text {THP }}$ & $K-1^{\Gamma P}$ & $\mathrm{~K}-2^{\Gamma \mathrm{HP}}$ & $K-2^{\Gamma P}$ & K-3 \\
\hline & & $\mathrm{K}-\mathrm{H}^{\mathrm{HS}}$ & & $\mathrm{K}-2^{\mathrm{HS}}$ & $\mathrm{K}-3$ & & $\mid K-1^{\mathrm{HS}}$ & & $K-2^{\mathrm{HS}}$ & $K-3$ \\
\hline \multicolumn{11}{|c|}{$\begin{array}{l}\text { Число углеродных атомов разного типа в средней молекуле } \\
\text { Number of different type carbon atoms in an average molecule }\end{array}$} \\
\hline$C_{a}$ & 33,6 & 15,6 & 18,2 & 6,9 & 7,2 & 23,6 & 15,1 & 11,2 & 6,0 & 8,4 \\
\hline$C_{n}$ & 39,8 & 14,0 & 17,5 & 15,4 & 9,8 & 29,0 & 12,8 & 20,4 & 10,4 & 7,0 \\
\hline$C_{p}$ & 9,8 & 17,8 & 10,8 & 3,6 & 7,9 & 2,9 & 10,1 & 1,5 & 4,6 & 6,8 \\
\hline \multicolumn{11}{|c|}{ Распределение атомов C, \%/Distribution of carbon atoms, \% } \\
\hline$f_{\mathrm{a}}$ & 40,4 & 32,9 & 39,0 & 26,6 & 29,0 & 42,6 & 39,8 & 33,8 & 28,5 & 38,0 \\
\hline$f_{\mathrm{n}}$ & 47,8 & 29,5 & 37,7 & 59,5 & 39,4 & 52,2 & 33,7 & 61,8 & 49,8 & 31,4 \\
\hline$\overline{f_{\mathrm{p}}}$ & 11,7 & 37,6 & 23,3 & 13,9 & 31,6 & 5,2 & 26,5 & 4,4 & 21,7 & 30,6 \\
\hline \multicolumn{11}{|c|}{$\begin{array}{l}\text { Число структурных единиц в молекуле } \\
\text { Number of structural units in a molecule }\end{array}$} \\
\hline$m_{a}$ & 2,6 & 1,7 & 1,8 & 1,1 & 1,2 & 2,1 & 1,6 & 1,4 & 1,1 & 1,2 \\
\hline \multicolumn{11}{|c|}{$\begin{array}{l}\text { Параметры средней структурной единицы } \\
\text { Parameters of average structural unit }\end{array}$} \\
\hline $\mathrm{K}_{\mathrm{t}}^{*}$ & 6,8 & 4,3 & 4,8 & 4,5 & 3,4 & 6,2 & 4,1 & \begin{tabular}{|l}
5,9 \\
\end{tabular} & 3,5 & 2,9 \\
\hline $\mathrm{K}_{\mathrm{a}}^{*}$ & 3,1 & 2,2 & 2,5 & 1,3 & 1,4 & 2,7 & 2,2 & 1,9 & 1,2 & 1,6 \\
\hline $\mathrm{K}_{\mathrm{n}}{ }^{*}$ & 3,7 & 2,1 & 2,3 & 3,2 & 2,0 & 3,5 & 1,9 & 4,0 & 2,3 & 1,3 \\
\hline $\mathrm{C}^{*}$ & 31,8 & 28,9 & 25,2 & 22,8 & 20,6 & 27,0 & 23,8 & 23,0 & \begin{tabular}{|l|}
19,7 \\
\end{tabular} & 17,8 \\
\hline $\mathrm{C}_{\mathrm{p}}{ }^{*}$ & 3,7 & 10,5 & 5,9 & 3,2 & 6,6 & 1,4 & 6,3 & 1,0 & 4,3 & 5,4 \\
\hline $\mathrm{C}_{\alpha}{ }^{*}$ & 4,8 & 4,5 & 4,2 & 3,4 & 3,7 & 4,0 & 3,6 & 3,7 & 3,2 & 3,2 \\
\hline $\mathrm{C}_{\gamma}{ }^{*}$ & 1,6 & 1,9 & 1,4 & 1,6 & 1,8 & 1,4 & 1,6 & 1,0 & 1,4 & 1,4 \\
\hline
\end{tabular}

$C_{a,} C_{n}, C_{p}-$ число ароматических, нафтеновых и парафиновых атомов углерода в средних молекулах; $f_{\mathrm{a}}, f_{\mathrm{n}}, f_{\mathrm{p}}$ - доли атомов углерода в ароматических, нафтеновых и парафиновых структурных фрагментах; \%; $m_{\text {a }}$ - число структурных единиц в средней молекуле; $K_{\mathrm{t}}{ }^{*}, K_{\mathrm{a}}{ }^{*}, K_{\mathrm{n}}{ }^{*}-$ - общее число, число ароматических и нафтеновых циклов в структурной единице; $C^{*}-$ общее число атомов углерода в структурной единице; $C_{p}{ }^{*}-$ число алкильных атомов углерода в структурной единице $C_{\alpha}{ }^{*}$ - количество атомов углерода, находящихся в $\alpha$-положении к ароматическим ядрам, $C_{\gamma}{ }^{*}-$ в не связанных с ароматическими ядрами терминальных метильных группах.

$C_{a}, C_{n}, C_{p}$ - number of aromatic, naphthenic and paraffinic carbon atoms in an average molecules; $f_{a}, f_{n}, f_{0}$ - fractions of carbon atoms in aromatic, naphthenic and paraffinic structural fragments, $\% ; m_{a}$ - number of structural units in the average molecule; $K_{t}{ }^{*}, K_{\mathrm{a}}{ }^{*}, K_{\mathrm{n}}{ }^{*}-$ total number, number of aromatic and naphthenic cycles in the structural unit; $C^{*}-$ total number of carbon atoms in the structural unit; $C_{n}^{*}-$ number of alkyl carbon atoms in the structural unit; $C_{\alpha}{ }^{*}$ - number of $C$ atoms in the $\alpha$-position to the aromatic nuclei, and $\mathrm{C}_{\gamma}{ }^{*}$ - in the terminal methyl groups not bound to the aromatic nuclei.

Для средних молекул АО термолизованных смол отмечена тенденция снижения количества и уменьшения размеров их структурных единиц $\left(\mathrm{m}_{\mathrm{a}}\right)$. Уменьшение общих размеров структурных единиц происходит главным образом за счет снижения числа углеродных атомов в парафиновых фрагментах $\left(\mathrm{C}_{\mathrm{p}}{ }^{*}\right)$. Наблюдается также снижение числа насыщенных $\left(K_{n}^{*}\right.$ ) и ароматических $\left(K_{\mathrm{a}}^{*}\right.$ *) циклов. В составе $\mathrm{C}_{\mathrm{p}}$ * уменьшается количество атомов углерода в метильных группах, удаленных от ароматического ядра $\left(\mathrm{C}_{\gamma}^{*}\right)$, что свидетельствует об уменьшении числа и/или степени разветвленности заместителей. Снижение значений параметра $\mathrm{C}_{\alpha}$ * указывает на уменьшение среднего числа заместителей у ароматических ядер.

Анализ продуктов $K-1^{\mathrm{rP}}, K-2^{\mathrm{rP}}$ и $K-3$ методом ГХ-МС показал, что в составе $\mathrm{A0}$ исходных и термолизованных смол присутствуют алкилзамещенные хинолины, бензо-, дибензохинолины и азапирены. Максимум в их распределении приходится на бензохинолины (табл. 5). Отличительной особенностью АО термолизованных смол является повышенное содержание алкилхинолинов. Увеличение доли бициклических азааренов может быть связано со строением молекул оснований $\mathrm{K}-1^{\mathrm{rP}}$, К-2 $2^{\text {гн }}$ исходных смол. По данным структурногруппового анализа (табл. 4) в структуру их средних единиц входят фрагменты, содержащие бициклоароматическое ядро $\left(\kappa_{a}^{*}=2,2 . .2,5\right)$ и два нафтеновых цикла $\left(K_{\sharp}^{*}=2,1 \ldots 2,3\right)$. К образованию алкилхинолинов, вероятнее всего, приводит термодеструкция таких оснований.

Таблица 5. Состав азоторганических оснований исходных и термолизованных смол

Table 5. Composition of organic nitrogen bases in the initial and thermolysed resins

\begin{tabular}{|c|c|c|c|c|}
\hline \multirow[b]{2}{*}{$\begin{array}{l}\text { Соединения } \\
\text { Compounds }\end{array}$} & \multicolumn{2}{|c|}{$\begin{array}{c}\text { Гомологические } \\
\text { ряды } \\
\text { Homologous series }\end{array}$} & \multicolumn{2}{|c|}{$\begin{array}{c}\text { Содержание, \% относи- } \\
\text { тельно идентифициро- } \\
\text { ванных структур } \\
\text { Content, \% of the rela- } \\
\text { tively identified structures }\end{array}$} \\
\hline & 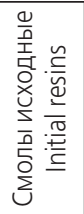 & 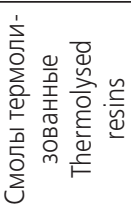 & 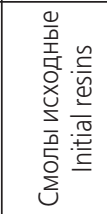 & 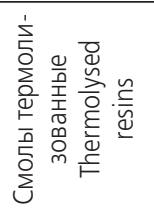 \\
\hline $\begin{array}{l}\text { Хинолины } \\
\text { Quinolines }\end{array}$ & $C_{2}-C_{10}$ & $C_{2}-C_{8}$ & 1,5 & 4,5 \\
\hline \begin{tabular}{|l|} 
Бензохинолины \\
Benzoquinolines
\end{tabular} & $C_{1}-C_{10}$ & $C_{1}-C_{6}$ & 87,0 & 88,1 \\
\hline $\begin{array}{l}\text { Дибензохинолины } \\
\text { Dibenzoquinolines }\end{array}$ & $C_{1}-C_{8}$ & $C_{2}-C_{3}$ & 9,1 & 1,6 \\
\hline $\begin{array}{l}\text { Азапирены } \\
\text { Azapyrenes }\end{array}$ & $C_{1}-C_{8}$ & $C_{1}-C_{4}$ & 2,5 & 5,8 \\
\hline
\end{tabular}

Кроме того, для термопреобразованных структур характерно менее развитое алкильное замещение и более высокая доля в их составе низкомолекулярных гомологов. В качестве примера на рис. 1, 2 приведено распределение алкилхинолинов и алкилбензохинолинов в $K-1^{\mathrm{rP}}$ исходных и термолизованных смол. 


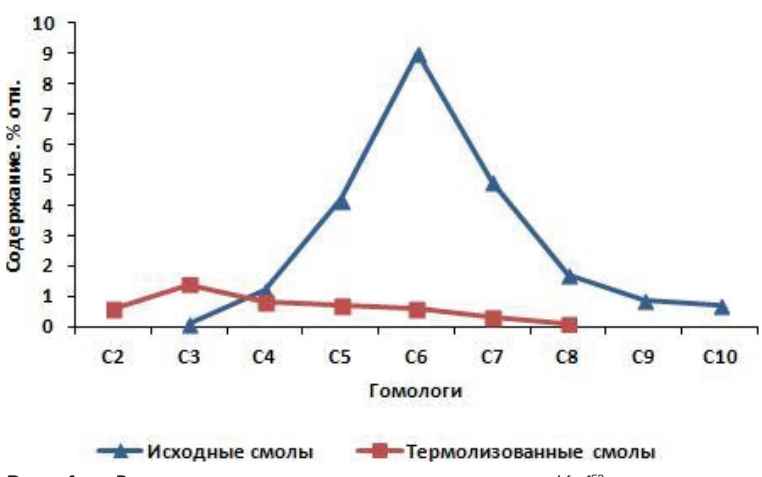

Рис. 1. Распределение алкилхинолинов в К-1 термолизованных смол

Fig. 1. Distribution of alkylquinolines in $\mathrm{K}-1^{\text {HS }}$ of the initial and thermolysed resins

\section{Заключение}

На основании проведенного исследования установлено, что азоторганические основания исходных и термопреобразованных $\left(450{ }^{\circ} \mathrm{C}, 30\right.$ мин, инертная среда) смол метано-нафтеновой нефти Крапивинского месторождения представлены высоко- и низкомолекулярными соединениями. Показано, что все азоторганические основания в термолизованных смолах являются продуктами деструкции высокомолекулярных соединений исходных смол. В обоих типах смол преобладают высокомолекулярные основания, однако их доля в термолизованных смолах существенно ниже. Термопреобразованные соединения имеют меньшие значения средних молекулярных масс, чем исходные. Их средние молекулы характеризуются повышенной ароматичностью за счет снижения доли нафтеновых и/или алкильных углеродных атомов.

\section{СПИСОК ЛИТЕРАТУРЫ}

1. Химический состав нефти Крапивинского месторождения / А.Э. Торломоева, Т.В. Чешкова, Е.Ю. Коваленко, Т.А. Сагаченко // Известия Томского политехнического университета. 2015. - T. 326. - № 2. - C. 48-55.

2. Химический состав нефти Крапивинского месторождения (сообщение 4) / Т.В. Чешкова, Н.Н. Герасимова, Т.А. Сагаченко, P.С. Мин // Известия Томского политехнического университета. Инжиниринг георесурсов. - 2017. - Т. 328. - № 8. C. $6-15$.

3. Prado G.H.C., Rao Y., De Klerk A. Nitrogen Removal from Oil: a Review // Energy Fuels. - 2017. - V. 31 - № 1. - P. 14-36.

4. Analysis of extractable basic nitrogen compounds in Buliangou subbituminous coal by positive-ion ESI FT-ICR MS / J. Kong, X.Y. Wei, H.L. Yan, Z.K. Li, M.X. Zhao, Y. Li, Z.M. Zong // Fuel. - 2015. - V. 159. - P. 385-391.

5. Characterization of basic heteroatom-containing organic compounds in liquefaction residue from Shenmu-Fugu subbituminous coal by positive-ion electrospray ionization Fourier transform ion cyclotron resonance mass spectrometry / P. Li, Z.M. Zong, Z.K. Li, Y.G. Wang, F.J. Liu, X.Y. Wei // Fuel Processing Technology. - 2015. - V. 132. - P. 91-98.

6. Synergistic Process for High Nitrogen Content Feedstocks Catalytic-Cracking: a Case Study of Controlling the Reactions of Ni-

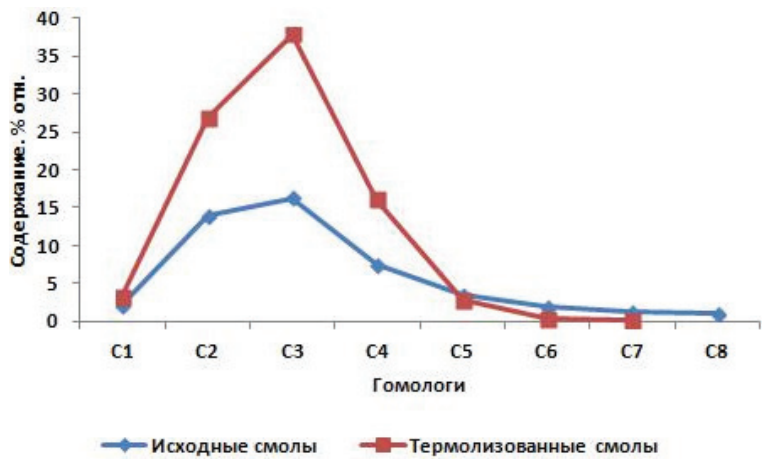

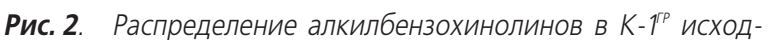
ных и термолизованных смол

Fig. 2. Distribution of alkylbenzoquinolines in $\mathrm{K}-1^{\text {ts }}$ of the initial and thermolysed resins

Среди оснований исходных и термолизованных смол присутствуют алкилпроизводные хинолина, бензохинолина, дибензохинолина и азапирена, максимум в распределении которых приходится на алкилбензохинолины. Отличительной особенностью состава азааренов термолизованных смол является повышенная доля бициклических соединений. Для термопреобразованных структур характерно менее развитое алкильное замещение и более высокая доля в их составе низкомолекулярных гомологов.

При термической переработке тяжелого углеводородного сырья идентифицированные соединения, которые являются ядами каталитических систем, войдут в состав дистиллятных фракций, что необходимо учитывать при выборе процессов их облагораживания.

trogen Compounds in Situ / J. Zhang, H. Shan, X. Chen, W. Liu, C. Yang // Industrial and Engineering Chemistry Research. 2014. - V. 53. - № 14. - P. 5718-5727.

7. Characterization of nitrogen-containing species in Huadian shale oil by electrospray ionization Fourier transform ion cyclotron resonance mass spectrometry / J. Tong, J. Liu, X. Han, S. Wang, X. Jiang // Fuel. - 2013. - V. 104. - P. 365-371.

8. High-active hydrotreating catalysts for heavy petroleum feeds: Intentional synthesis of CoMo sulfide particles with optimal localization on the support surface / A.V. Pashigreva, O.V. Klimov, G.A. Bukhtiyarova, D.I. Kochubey, I.P. Prosvirin, Yu.A. Chesalov, V.I. Zaikovskii, A.S. Noskov // Catalysis Today. - 2010. V. 150. - № 3-4. - P. 164-170.

9. Transformation of nitrogen-containing compounds in atmospheric residue by hydrotreating / M. Liu, L.Z. Zhang, C. Zhang, S.H. Yuan, L.H. Duan // Korean Journal of Chemical Engineering. - 2018. - V. 35. - № 2. - P. 375-382.

10. Structure and Composition Changes of Nitrogen Compounds during the Catalytic Cracking Process and their Deactivating Effect on Catalysts / X. Chen, Y. Liu, S. Li, X. Feng, H. Shan, C. Yang // Energy Fuels. - 2017. - V. 31. - № 4. - P. 3659-3668.

11. Molecular Transformation of Crude Oil in Confined Pyrolysis System and its Impact on Migration and Maturity Geochemical Parameters / Y. Zhang, Y. Liao, S. Guo, C. Xu, Q. Shi // Energy Fuels. - 2016. - V. 30. - № 9. - P. 6923-6932. 
12. Rocha Y.D., Pereira R.C.L., Mendonca J.G. Negative electrospray Fourier transform ion cyclotron resonance mass spectrometry determination of the effects on the distribution of acids and nitrogen-containing compounds in the simulated thermal evolution of a Type-I source rock // Organic Geochemistry. - 2018. V. $115 .-$ P. $32-45$.

13. Азотсодержащие основания смол тяжёлой нефти Усинского месторождения / Н.Н. Герасимова, А.С. Классен, Р.С. Мин, Т.А. Сагаченко // Химия в интересах устойчивого развития. 2016. - T. 24. - № 6. - C. 739-744.

14. Аюрова А.М., Герасимова Н.Н., Сагаченко Т.А. Высокомолекулярные и низкомолекулярные азотистые основания в высокопарафинистых нефтях // Известия Томского политехнического университета. Инжиниринг георесурсов. - 2017. T. 328. - № 2. - C. $28-35$.

15. Okuno I., Latham D.R., Haines W.E. Type Analysis of Nitrogen in Petroleum Using Nonaqueous Potentiometric Titration and Lithium Aluminum Hydride Reduction // Analytical Chemistry. - 1965. - V. 37. - № 1. - P. 54-57.

16. Современные методы исследования нефтей (справочно-методическое пособие) / под ред. А.И. Богомолова, М.Б. Темянко, Л.И. Хотынцевой. - Л.: Недра, 1984. - 431 с.
17. Fergoug T., Bouhadda Y. Determination of Hassi Messaoud asphaltene aromatic structure from H-1 \& C-13 NMR analysis // Fuel. - 2014. - V. 115. - № 1. - P. 521-526.

18. Golovko A.K., Kam'yanov V.F., Ogorodnikov V.D. High-molecular heteroatomic components of crude oils of the Timan-Pechora petroliferous basin // Russian Geology and Geophysics. - 2012. V. 53. - № 12. - P. 1374-1381.

19. Thermal cracking of substituted cholestane-benzoquinoline asphaltene model compounds (Conference Paper) / A.N. Alshareef, A. Scherer, J.M. Stryker, M.R. Gray // Energy Fuels. 2012. - V. 26. - № 6. - P. 3592-3603.

20. Speight Jg. Thermal transformations of asphaltenes // Petroleum Chemistry. - 1989. - V. 29. - № 4. - P. 253-261.

21. Антипенко В.Р. Термические превращения высокосернистого природного асфальтита: Геохимические и технологические аспекты. - Новосибирск: Наука, 2013. - 184 с.

Поступила 17.04.2018 г.

\section{Информация об авторах}

Герасимова H.H., кандидат химических наук, доцент, старший научный сотрудник лаборатории гетероорганических соединений нефти Института химии нефти Сибирского отделения Российской академии наук.

Сагаченко T.A., доктор химических наук, ведущий научный сотрудник лаборатории гетероорганических соединений нефти Института химии нефти Сибирского отделения Российской академии наук.

Мин P.C., доктор химических наук, заведующая лабораторией гетероорганических соединений нефти Института химии нефти Сибирского отделения Российской академии наук. 
UDC 665.64:547.83

\title{
TRANSFORMATIONS OF ORGANIC NITROGEN BASES IN RESIN COMPONENTS OF OIL RECOVERED FROM THE KRAPIVINSK DEPOSIT AT THERMAL TREATMENT
}

\author{
Natalia N. Gerasimova', \\ dm@ipc.tsc.ru \\ Tatyana A. Sagachenko', \\ dissovet@ipc.tsc.ru \\ Raisa S. Min' \\ lgosn@ipc.tsc.ru \\ 1 Institute of Petroleum Chemistry of Siberian Branch of the Russian Academy of Sciences, \\ 4, Akademichesky Avenue, 634055, Tomsk, Russia.
}

The relevance of the work is caused by the need to obtain information on thermal stability of organic nitrogen bases in resin components of the Upper Jurassic methano-naphthenic oil recovered from the Krapivinsk deposit located in the Tomsk Region to solve the problems associated with oil processing.

The aim of the research is to obtain data on directions of thermal transformation of organic nitrogen bases in oil resins recovered from the Krapivinsk deposit.

Methods: complexing, extraction, ${ }^{1} H$ NMR spectroscopy, structural-group analysis, chromatography-mass spectrometry.

Results. Based on the study of compositions and structures of organic nitrogen bases in the resins of the Krapivinsk oil before and after thermal treatment $\left(450^{\circ} \mathrm{C}, 30 \mathrm{~min}\right.$, inert medium), it was shown that at thermolysis under the selected conditions the partial destruction of high-molecular bases and complete loss of low-molecular bases occur. All bases in the thermolysed resins are the transformation products of high-molecular compounds in the initial resins. It was found that high-molecular compounds constituted a major part of the bases in the resins before and after thermal treatment, however their portion in the thermolysed resins was much lower. ThermaIly transformed bases have lower average molecular weights as compared with the initial ones. The compositions of the isolated compounds were studied by structural-group analysis and gas chromatography-mass spectrometry. It was shown that average molecules of the organic nitrogen bases of both resin types were composed of aromatic, naphthenic and alkyl fragments. In the average molecules of the compounds in the thermolysed resins the portion of aromatic carbon atoms was higher due to a decreased portion of naphthenic and alkyl carbon atoms. Alkyl derivatives of quinoline, benzoquinoline, dibenzoquinoline and azapyren, among which alkyl benzoquinolines predominate, are presented in the initial and thermolysed resin bases. An increased content of alkylquinolines is a feature of azaarenes in the thermolysed resins. Less developed alkyl substitution and a higher portion of low-molecular homologues are typical for thermally transformed structures.

\section{Key words:}

Resins, organic nitrogen bases, thermal transformations, content, composition, structural-group analysis, chromatography-mass spectrometry.

\section{REFERENCES}

1. Torlomoyeva A.E., Cheshkova T.V., Kovalenko E.Yu., Sagachenko T.A. Chemical composition of petroleum of Krapivinskoe oilfield. Bulletin of the Tomsk Polytechnic University, 2015, vol. 326, no. 2, pp. 48-55.

2. Cheshkova T.V., Gerasimova N.N., Sagachenko T.A., Min R.S. Chemical composition of petroleum from Krapivinskoe oilfield (message 4). Bulletin of the Tomsk Polytechnic University. Geo As sets Engineering, 2017, vol. 328, no. 8, pp. 6-15.

3. Prado G.H.C., Rao Y., De Klerk A. Nitrogen Removal from Oil: a Review. Energy Fuels, 2017, vol. 31, no. 1, pp. 14-36.

4. Kong J., Wei X.Y., Yan H.L., Li Z.K., Zhao M.X., Li Y., Zong Z.M. Analysis of extractable basic nitrogen compounds in Buliangou subbituminous coal by positive-ion ESI FT-ICR MS. Fuel, 2015, vol. 159, pp. 385-391.

5. Li P., Zong Z.M., Li Z.K., Wang Y.G., Liu F.J., Wei X.Y. Characterization of basic heteroatom-containing organic compounds in liquefaction residue from Shenmu-Fugu subbituminous coal by positive-ion electrospray ionization Fourier transform ion cyclotron resonance mass spectrometry. Fuel Processing Technology, 2015, vol. 132 , pp. 91-98.

6. Zhang J., Shan H., Chen X., Liu W., Yang C. Synergistic Process for High Nitrogen Content Feedstocks Catalytic-Cracking: a Case Study of Controlling the Reactions of Nitrogen Compounds in Si- tu. Industrial and Engineering Chemistry Research, 2014, vol. 53, no. 14, pp. 5718-5727.

7. Tong J., Liu J., Han X., Wang S., Jiang X. Characterization of nitrogen-containing species in Huadian shale oil by electrospray ionization Fourier transform ion cyclotron resonance mass spectrometry. Fuel, 2013, vol. 104, pp. 365-371.

8. Pashigreva A.V., Klimov O.V., Bukhtiyarova G.A., Kochubey D.I., Prosvirin I.P., Chesalov Yu.A., Zaikovskii V.I., Noskov A.S. High-active hydrotreating catalysts for heavy petroleum feeds: Intentional synthesis of CoMo sulfide particles with optimal localization on the support surface. Catalysis Today, 2010, vol. 150, no. 3-4, pp. 164-170.

9. Liu M., Zhang L.Z., Zhang C., Yuan S.H., Duan L.H. Transfjrmation of nitrogen-containing compounds in atmospheric residue by Hydrotreating. Korean Journal of Chemical Engineering, 2018, vol. 35 , no. 2, pp. 375-382.

10. Chen X., Liu Y., Li S., Feng X., Shan H., Yang C. Structure and Composition Changes of Nitrogen Compounds during the Catalytic Cracking Process and their Deactivating Effect on Catalysts. Energy Fuels, 2017, vol. 31, no. 4, pp. 3659-3668.

11. Zhang Y., Liao Y., Guo S., Xu C., Shi Q. Molecular Transformation of Crude Oil in Confined Pyrolysis System and its Impact on Migration and Maturity Geochemical Parameters. Energy Fuels, 2016, vol. 30, no. 9, pp. 6923-6932. 
12. Rocha Y. D., Pereira R.C.L., Mendonca J.G. Negative electrospray Fourier transform ion cyclotron resonance mass spectrometry determination of the effects on the distribution of acids and nitrogen-containing compounds in the simulated thermal evolution of a Type-I source rock. Organic Geochemistry, 2018, vol. 115 , pp. $32-45$.

13. Gerasimova N.N., Klassen A.S., Min R.S., Sagachenko T.A. Azotsoderzhashchie osnovaniya smol tyazheloy nefti Usinskogo mestorozhdeniya [Nitrogen-Containing Resin Bases from Heavy Oils of the Usinsk Deposit]. Chemistry for Sustainable Development, 2016, vol. 24, no. 6, pp. 739-744.

14. Ayurova A.M., Gerasimova N.N., Sagachenko T.A. High- and low-molecular nitrogenous bases in highly paraffinic oils. Bulletin of the Tomsk Polytechnic University. Geo Assets Engineering, 2017, vol. 328, no. 2, pp. 28-35.

15. Okuno I., Latham D.R., Haines W.E. Type Analysis of Nitrogen in Petroleum Using Nonaqueous Potentiometric Titration and Lithium Aluminum Hydride Reduction. Analytical Chemistry, 1965, vol. 37, no. 1, pp. 54-57.

16. Sovremennye metody issledovaniya neftey: spravochno-metodicheskoe posobie [Modern methods of oil research: reference benefit]. Eds. Bogomolov A.I., Temyanko M.B., Khotyntseva L.I. Leningrad, Nedra Publ., 1984. 431 p.

\section{Information about the authors}

Natalia N. Gerasimova, Cand. Sc., associate professor, senior researcher, Institute of Petroleum Chemistry of Siberian Branch of the Russian Academy of Sciences.

Tamyana A. Sagachenko, Dr. Sc., chief researcher, Institute of Petroleum Chemistry of Siberian Branch of the Russian Academy of Sciences.

Raisa S. Min, Dr. Sc., head of the Laboratory of Heteroorganic Petroleum Compounds, Institute of Petroleum Chemistry of Siberian Branch of the Russian Academy of Sciences.
17. Fergoug T., Bouhadda Y. Determination of Hassi Messaoud asphaltene aromatic structure from H-1 \& C-13 NMR analysis. Fuel, 2014, vol. 115, no. 1, pp. 521-526.

18. Golovko A.K., Kam'yanov V.F., Ogorodnikov V.D. High-molecular heteroatomic components of crude oils of the Timan-Pechora petroliferous basin. Russian Geology and Geophysics, 2012, vol. 53, no. 12, pp. 1374-1381.

19. Alshareef A.N., Scherer A., Stryker J.M., Gray M.R. Thermal cracking of substituted cholestane-benzoquinoline asphaltene model cjmpounds (Conference Paper). Energy and Fuels, 2012, vol. 26 , no. 6 , pp. 3592-3603.

20. Speight Jg. Thermal transformations of asphaltenes. Petroleum Chemistry, 1989, vol. 29, no. 4, pp. 253-261.

21. Antipenko V.R. Termicheskie prevrashcheniya vysokosernistogo prirodnogo asfaltita: Geokhimicheskie i tekhnologicheskie aspekty [Thermal transformations of a sulphur-rich natural asphaltite: Geochemical and technological aspects]. Novosibirsk, Nauka Publ., 2013. 184 p.

Received: 17 April 2018. 